Revue d'histoire de l'Amérique française

ZRS REVUE D.HISTOIRE DE L'AMÉRIQUE FRANÇAISE

\title{
Prix littéraires de l'Institut d'histoire de l'Amérique française
}

Volume 56, numéro 1, été 2002

URI : https://id.erudit.org/iderudit/007241ar

DOI : https://doi.org/10.7202/007241ar

Aller au sommaire du numéro

Éditeur(s)

Institut d'histoire de l'Amérique française

ISSN

0035-2357 (imprimé)

1492-1383 (numérique)

Découvrir la revue

Citer ce document

(2002). Prix littéraires de l'Institut d'histoire de l'Amérique française. Revue d'histoire de l'Amérique française, 56(1), 145-148.

https://doi.org/10.7202/007241ar d'utilisation que vous pouvez consulter en ligne.

https://apropos.erudit.org/fr/usagers/politique-dutilisation/ 


\title{
PRIX L I T T É RA I R E S de l'Institut d'histoire de l'Amérique française
}

\begin{abstract}
T e i8 octobre Dernier, dans le cadre de son $55^{\mathrm{e}}$ congrès annuel, tenu ـà l'hôtel Delta à Sherbrooke, l'Institut d'histoire de l'Amérique française procédait à la remise de ses prix littéraires.
\end{abstract}

PRIX LIONEL-GROULX - FONDATION YVES-SAINT-GERMAIN

Doté d'une bourse de 5000 \$, le Prix Lionel-Groulx — Fondation YvesSaint-Germain est le plus prestigieux des prix offerts par l'Institut d'histoire de l'Amérique française. Il récompense le meilleur ouvrage paru en 2001, portant sur un aspect de l'histoire de l'Amérique française et s'imposant par son caractère scientifique.

Gervais Carpin a mérité le Prix Lionel-Groulx pour son étude des mouvements migratoires de la France vers la Nouvelle-France entre 1628 et 1662 intitulé Le réseau du Canada. Étude du mode migratoire de la France vers la Nouvelle-France (1628-1662), publié chez Septentrion et aux Presses de l'Université de Paris-Sorbonne. Il met finement en relief le rôle de Richelieu, de la Compagnie de la Nouvelle-France et des agents recruteurs pour venir ainsi compléter l'historiographie de l'immigration $\mathrm{au} \mathrm{XVII}^{\mathrm{e}}$ siècle. On retient son approche novatrice à partir du concept de réseau pour appréhender le processus migratoire des quelque 7000 départs qu’il a retracés. Les spécialistes en Nouvelle-France seront reconnaissants à Gervais Carpin d'avoir apporté un éclairage nouveau sur un sujet de grand intérêt.

L'auteur est détenteur d'un doctorat en histoire de l'Université Laval et ce livre est tiré de sa thèse soutenue en 1999. En 1995, il a publié, aux Éditions du Septentrion, Histoire d'un mot. L'ethnonyme "Canadien" de 1535 à 1691. 


\section{PRIX GUY-ET-LILIANNE-FRÉGAULT}

Offert par la famille Frégault et d'une valeur de 1000 \$, le Prix GuyFrégault couronne le meilleur article publié dans le volume 55 (20012002) de la Revue d'histoire de l'Amérique française.

De plus en plus les spécialistes en histoire confrontent les représentations d'un événement ou d'un peuple et la réalité, en autant que celleci puisse se laisser cerner. Un des thèmes ainsi déconstruit est l'antimodernisme québécois. L’article de James Murton, «La "Normandie du Nouveau Monde" : la société Canada Steamship Lines, l'antimodernisme et la promotion du Québec ancien », retrace la construction du mythe de l'habitant québécois, construit par la publicité d'une compagnie maritime destinée surtout aux Américains et encouragée par le développement de l'artisanat, dans le but de répondre aux exigences du marché touristique. Une étude originale, fouillée et qui laisse voir un passé complexe dont l'interprétation n'est pas sans conséquences aujourd'hui.

\section{PRIX MICHEL-BRUNET}

D’une valeur de 1000 \$, le Prix Michel-Brunet couronne le meilleur ouvrage publié depuis moins de deux ans par un historien ou une historienne québécoise de moins de 35 ans.

Depuis quelques années de nombreux historiens et historiennes sont passés de la mémoire recelée dans les archives à celle des paysages. Cette année, ce prix est décerné à une jeune historienne qui a su faire parler les pierres du paysage bâti: celles du quartier Saint-Roch à Québec. Dans La mémoire du paysage. Histoire de la forme urbaine d'un centre-ville: Saint-Roch, Québec, publié aux Presses de l'Université Laval, Lucie K. Morisset interroge, de la Nouvelle-France à nos jours, les murs, les cimetières, les maisons et les usines ainsi que leurs représentations cartographiées, gravées puis photographiées qui se superposent, pour en dégager "comme un palimpseste» selon l'expression de l'auteure. Une superbe exploitation de l'iconographie illustre les transformations, les stratifications vécues par un quartier devenu vivant sous la plume de Lucie Morisset.

Historienne d'architecture, Lucie K. Morisset est professeure au département d'études urbaines et touristiques de l'Université du Québec à Montréal. Elle a signé plusieurs ouvrages et articles sur l'architecture et sur l'histoire de la forme urbaine au Québec. 


\section{PRIX MAXIME-RAYMOND}

Le Prix Maxime-Raymond a été créé par la Fondation Lionel-Groulx. D’une valeur de $1500 \$$, il couronne la meilleure biographie historique publiée en français dans les trois années précédant sa remise et s'imposant par son caractère scientifique.

Un des avantages d'être membre d'un jury tel que celui-ci, c'est qu'il nous arrive de découvrir de très beaux livres. L'ouvrage que nous voulons honorer par le Prix Maxime-Raymond pour la meilleure biographie séduit par sa présentation autant que par ses textes. Le Musée du Québec et le Musée des Beaux-Arts de Montréal ont de quoi être fiers du catalogue de l'exposition Louis-Philippe Hébert produit sous la direction de Daniel Drouin. Les articles des auteurs, trop nombreux pour tous être nommés ici, couvrent les principaux aspects de la vie et de l'œuvre du sculpteur, et nous offrent un artiste dans son contexte historique à Montréal, à Paris et partout où on retrouve ses monuments. Pour ne mentionner qu'un article, nous aimerions souligner particulièrement l'article d'Antoinette Le Normand-Romain sur "Hébert à Paris».

Cette année, le jury était composé d'Andrée Lévesque, de l'Université McGill, de Béatrice Craig, de l'Université d'Ottawa, et de Jacques Mathieu, de l’Université Laval.

\section{PRIX HISTORIA D'EXCELLENCE EN PRODUCTION DOCUMENTAIRE HISTORIQUE}

Le Prix Historia d'excellence en production documentaire historique est décerné par l'Institut d'histoire de l'Amérique française, selon les critères de sélection suivants: la valeur historique du document, la qualité audiovisuelle de production et l'efficacité de la communication. Dix productions étaient en compétition cette année.

Le jury a sélectionné deux films - l'un aborde un sujet politique, l'autre traite de l'histoire culturelle. Le jury a accordé une "mention spéciale» au film RIN, produit par Monique Simard, des productions Virage, et réalisé par Jean-Claude Labrecque. Ce film sur le Rassemblement pour l'indépendance nationale retrace l'histoire de ce parti, qui, malgré sa brève existence, a changé le paysage politique en faisant de l'indépendance un thème majeur de la vie intellectuelle du Québec. Le jury a été frappé par la simplicité du film, son respect de la vérité ainsi que par la force et l'excellence des témoignages, particulièrement ceux de Pierre Bourgault et d'André d'Allemagne. 
Le Prix Historia est accordé à Anna Malenfant d'Acadie, produit par Céline Chevrier pour Phare-Est Inc., et réalisé par Ginette Pellerin. Le film, qualifié par le jury d' "attachant» et de "captivant», raconte l'histoire de la contralto Anna Malenfant. Bien que peu connue, Anna Malenfant, née en 1902, fut une des grandes cantatrices canadiennes de son temps. Sous le pseudonyme de Marie Le Brun, elle figure également parmi les pionniers de la chanson québécoise. Le jury a été impressionné par la rigueur historique du documentaire, la qualité des entrevues, la valeur humaine du document, par la justesse des reconstitutions et le scénario soigné. Il faut souligner aussi la qualité de la production et son intérêt historique puisqu'elle nous fait découvrir une personnalité peu connue de notre histoire. Le film, simple et séduisant, devrait toucher un large public. Anna Malenfant d'Acadie, pour toutes ces raisons, mérite de remporter le premier Prix Historia.

Le jury, nommé par l'Institut d'histoire de l'Amérique française, était composé du cinéaste Jacques Godbout, des historiens Denis Vaugeois et Brian Young. 